\title{
Laju Kesalahan Bit Sistem Transmisi OFDM-BPSK Akibat Variasi Cyclic Prefix pada Guard Interval
}

\author{
Rahmad Hidayat \\ Jurusan Teknik Elektro \\ Sekolah Tinggi Teknologi Mandala \\ Bandung, Indonesia \\ Email : rhidayat4000@gmail.com
}

\begin{abstract}
Abstrak-Laju kesalahan bit (Bit Error Rate, BER) merupakan satu parameter utama kinerja sistem komunikasi digital. Tulisan ini memberikan kajian BER akibat adanya penambahan Cyclic Prefix (CP) pada guard interval yang ada pada simbol kanal transmisi OFDM yang dipakai oleh banyak aplikasi komunikasi digital saat ini. Tujuannya adalah untuk melihat pergeseran nilai kurva BER tersebut dan pengaruhnya akibat variasi beberapa nilai CP. Dengan skema modulasi BPSK dan kanal additive white gaussian noise (AWGN) pada simulasi Matlab diperoleh hasil bahwa harga laju kesalahan bit yang aman $0,9 \times 10^{-5}$ untuk Eb/No $10 \mathrm{~dB}$ pada simulasi ini diperoleh pada maksimum CP $28,6 \%$.
\end{abstract}

Kata kunci-OFDM,BER, cyclic prefix, guard interval, Eb/No

\section{Pendahuluan}

OFDM (Orthogonal Frequency Division Multiplexing) banyak dipakai untuk sistem komunikasi wireless mengingat kemampuan dari OFDM mengatasi multipath fading yang menyebabkan terjadinya intersymbol interference (ISI). Dampak dari ISI tersebut adalah penerima tidak dapat membaca kode informasi dengan benar sehingga mengurangi kinerja sistem komunikasi digital. Cara OFDM mengatasi ISI adalah dengan menggandakan simbol dan menambah sejumlah simbol secara periodik yang digunakan sebagai guard interval. Terkait hal di atas, maka menjadi sesuatu yang menarik bagi penulis untuk mengkaji pengaruh penambahan Cyclic Prefix sebagai guard interval terhadap laju kesalahan bit sistem transmisi OFDM BPSK. Diharapkan dengan kajian ini akan lebih mendorong penelitian mendalam sistem transmisi OFDM secara umum guna menyumbangkan pemikiran, analisis, purwarupa ataupun teori baru bagi pemanfaatan dalam banyak bidang komunikasi digital.

\section{GUARD INTERVAL PADA OFDM}

OFDM merupakan suatu teknik transmisi yang menggunakan beberapa buah frekuensi pembawa (multicarrier) dalam satu saluran dimana setiap frekuensi pembawa tersebut saling orthogonal (tegak lurus).

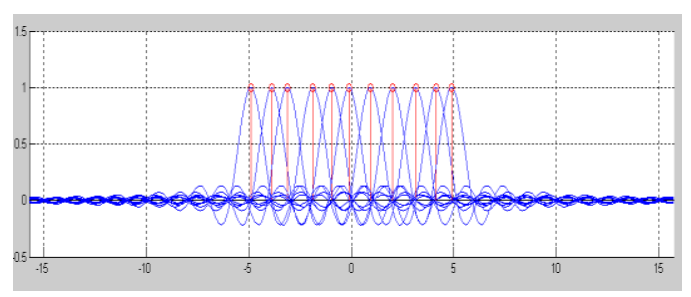

Gbr.1 Sinyal orthogonal pada spektrum OFDM

Dikarenakan pada setiap frekuensi pembawa tersebut sudah saling orthogonal maka akan terjadi tumpang tindih pada setiap frekuensi pembawa yang bersebelahan dimana pada setiap frekuensi pembawa tersebut dipisahkan guard interval berupa cyclic prefix $(C P)$. Penambahan band guard ini yang terlalu lebar bisa mengurangi throughput data yang dikirimkan [1].

\section{A. Blok OFDM}

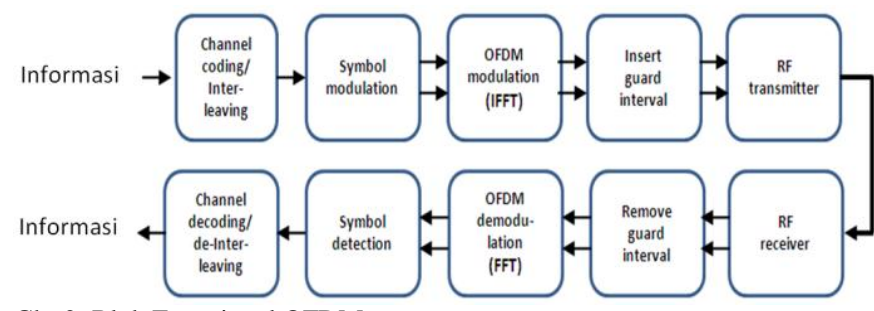

Gbr.2 Blok Fungsional OFDM

Pada gambar blok diagram fungsional di atas, terlihat pada sisi kirim, sinyal informasi pertama-tama dikodekan untuk menambah redundansi bagi proses error recovery dan disisipkan untuk mengacak efek error kanal. Bit-bit yang ada kemudian dipetakan menjadi simbol-simbol pada tiap subcarrier dengan menggunakan skim modulasi klasik seperti BPSK, QPSK atau QAM. Sinyal OFDM multi sub-carrier kemudian dibangun menggunakan pemrosesan sinyal digital (Digital Signal Processing, DSP) dengan teknik IFFT (invers fast fourier transform) dan dilakukan penyisipan interval guard untuk memelihara orthogonalitas (noninterferensi) simbolsimbol pada lingkungan multipath. Pada sisi terima , interval guard tersebut dibuang dan digunakan FFT (fast fourier transform) untuk membangkitkan kembali (demodulasi) sinyal multi subcarrier. Kemudian proses deteksi simbol akan 
memutuskan apakah simbol telah diterima dan menerjemahkannya menjadi bit-bit, kemudian dilakukan pengeluaran (deinterleaved) sinyal asal dan pendekodean menjadi sinyal informasi asli sesuai yang dikirim.

\section{B. Penambahan Guard Interval}

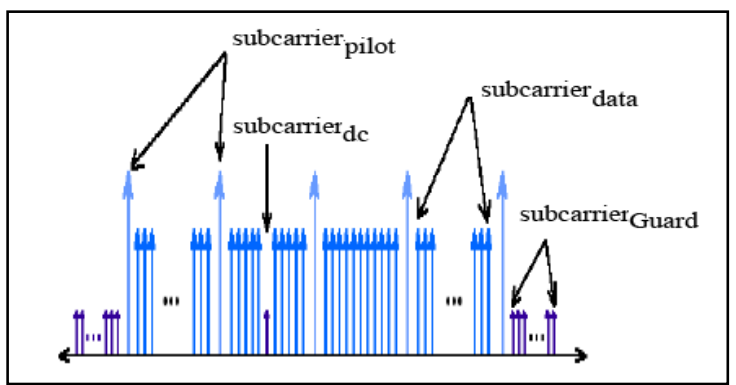

Gbr.3 Susunan subcarrier pada simbol OFDM

Ketika saluran melewati saluran dispertif waktu, orthogonalitas dari OFDM dapat berubah. Cyclic prefix (CP) dapat membantu menjaga keorthogonalitasan dari sinyal OFDM tersebut. Pada mulanya sebelum ada cyclic prefix $(\mathrm{CP})$ jarak antara subcarrier diisi dengan guard interval. Dalam prakteknya ternyata antara subcarrier tersebut yang berisikan guard interval menimbulkan intercarrier interference (ICI) karena adanya crosstalk antara subcarrier yang berbeda sehingga hal tersebut akan menimbulkan hilangnya orthogonalitas dari sinyal OFDM. Cyclic prefix merupakan salinan (copy) dari bagian akhir simbol OFDM yang ditaruh di depan pada saat pengiriman sinyal OFDM. Gbr.4 memperlihatkan definisi cyclic prefix yang digunakan sebagai guard interval pada sistem OFDM. [2][3]

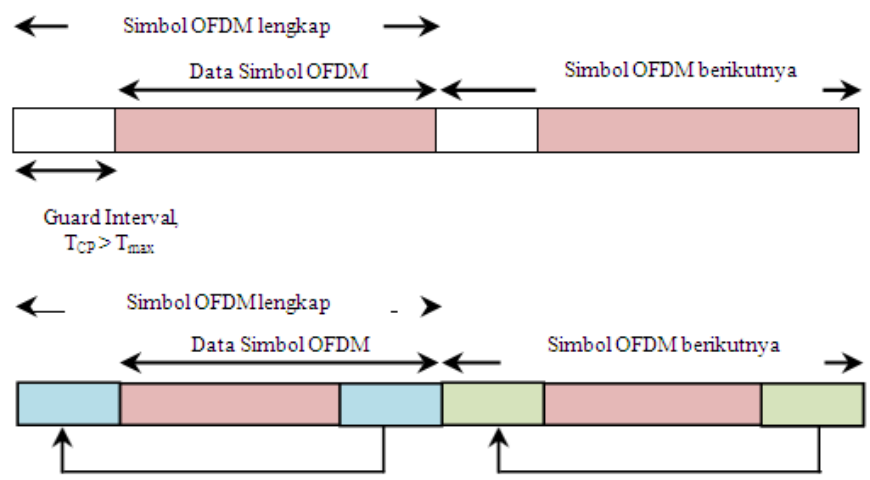

Gbr.4 Cyclic prefix (CP) pada guard interval OFDM.[3]

Cyclic prefix atau yang disingkat dengan CP berfungsi sebagai guard interval yang memastikan semua simbol OFDM terkirim secara lengkap dalam interval FFT dengan waktu tunda yang sama. Hal ini akan menjaga keorthogonalitasan dari sinyal OFDM. Pada modulasi OFDM, IFFT diambil sebagai perioda simbol sehingga secara teknisnya akan dihasilkan waktu yang sama. Pada transformasi fourier akan dihasilkan komponen dari semua sinyal yang saling orthogonal. Pada bagian penerima cyclic prefix tersebut dibuang sebelum proses demodulasi dengan
FFT. Selama interval CP tersebut tidak melebihi delay spread maksimum $\tau_{\max }$, semua pantulan dari simbol sebelumnya dibuang dan keorthogonalitasan sinyal dipulihkan. Jika interval cyclic prefix melebihi delay spread maksimum $\tau_{\max }$ maka keorthogonalitasan sinyal tersebut akan hilang.[3] Dalam proses pembangkitannya, CP di-copykan dari misal 16 sampel terakhir $\left(16 T_{S}\right)$ dari frame simbol OFDM untuk ditambahkan ke awal frame simbol berikutnya "unpublished" [4]. Tiap sampel memiliki periode $T_{S}$ dan total dalam satu frame ada $64 T_{S}$. Pada sisi penerima, CP tersebut dibuang sehingga yang masuk ke proses ekualisasi tetap sebanyak $64 T_{S}$.

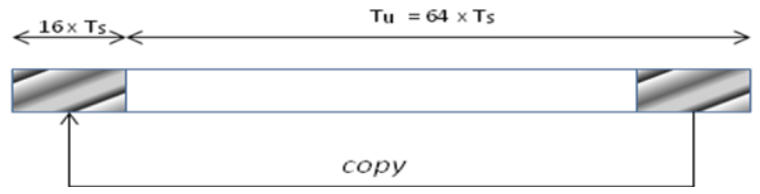

Gbr.5 Proses copy CP pada frame

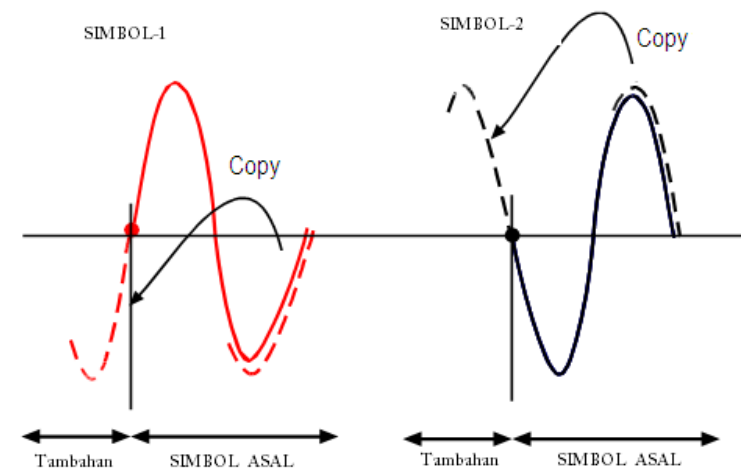

Gbr.6 Proses copy CP pada subcarrier [5]

Referensi [6] menyebutkan bahwa untuk melindungi sinyal OFDM dari gangguan pada kanal maka ditambahkan CP. Panjang CP bervariasi, tetapi kondisi ideal saat panjang CP ini sesuai dengan respon impuls kanal. Jika panjang respon impuls kanal $=L$, maka untuk menambah $\mathrm{CP}$ dilakukan copy nilai L terakhir dari sinyal waktu kemudian sisipkan pada bagian awal dari sinyal waktu tersebut. Pada model OFDM terprogram, panjang CP tidak dapat lebih dari jumlah carrier yang ada. Penambahan CP meningkatkan kecepatan simbol menjadi :

$$
R^{v}=\frac{R\left[1+\frac{w}{N}\right]}{R W} \quad\left(\frac{b i t}{g}\right)
$$

dengan $\quad K=$ jumlah bit per simbol (bit)

$N=$ jumlah carrier

$R=$ kecepatan data $(\mathrm{bit} / \mathrm{s})$ 


\section{FFT dan IFFT}

Fast Fourier Transform (FFT) adalah algoritma transformasi fourier yang dikembangkan dari algoritma Discrete Fourier Transform (DFT) untuk meningkatkan laju komputasi dari perhitungan transformasi fourier yaitu dengan mereduksi proses looping pada kalkulasi DFT tersebut sehingga hasilnya FFT tersebut mengurangi pemakaian memori dan mempercepat kerja sistem yang menggunakannya. FFT dapat mengambil sinyal acak, mengalikannya berturut-turut dengan eksponensial kompleks selama rentang frekuensi yang ada, menjumlahkan setiap hasil dan melakukan plot hasil tersebut sebagai koefisien frekuensi. Koefisien ini disebut spektrum dan mewakili "berapa banyak" frekuensi yang terdapat dalam sinyal input. Sinyal hasil FFT berbentuk domain frekeunsi. [6,7,8]

Kita dapat menulis FFT dalam sinusoidal sebagai :

$$
x(k)=\sum_{n=0}^{W-1} x(n) \sin \left[\frac{2-m}{\mathbb{N}}\right]+j \sum_{n=\mathbb{D}}^{W} x(n) \cos \left[\frac{2 \pi m}{\mathbb{W}}\right]
$$

$x(n)$ adalah koefisien sinus dan cosinus dari $2 \pi \mathrm{k} / \mathrm{N}$, dimana $\mathrm{k}$ adalah indeks dari frekuensi dari $\mathrm{N}$ buah frekuensi dan $\mathrm{n}$ adalah indeks waktu. $\mathrm{X}(\mathrm{k})$ adalah nilai dari spektrum untuk frekuensi $k_{\text {th }}$ dan $x(n)$ adalah nilai dari sinyal pada waktu $n$. Koefisien yang ada didefinisikan sebagai sampel domain waktu $x(k)$ untuk FFT dan nilai bin $X(n)$ frekuensi untuk IFFT.

Invers Fast Fourier Transform (IFFT) mengambil spektrum yang diterima dan mengubah semuanya kembali ke sinyal domain waktu dengan cara mengalikannya dengan sejumlah gelombang sinus. Persamaan IFFT terlihat pada (3).

$$
X(n)=\sum_{m=0}^{W-1} x(k) \sin \left[\frac{2-m}{M}\right]-j \sum_{n=0}^{W-1} x(k) \cos \left[\frac{2-n w}{M}\right]
$$

\section{BER (Bit Error Ratio) dan Eb/No}

Bit Error Rate $(B E R)$ adalah perbandingan jumlah bit salah yang diterima receiver terhadap jumlah bit yang dikirim. Dalam realisasinya $B E R$ sangat dipengaruhi oleh noise karena noise dapat menyebabkan adanya kesalahan proses deteksi. Sedangkan Eb/No menyatakan besarnya perbandingan Energi bit terhadap Noise (derau). Terdapat parameter utama dalam komunikasi berupa Signal to Noise Ratio $(\mathrm{S} / \mathrm{N})$ yang memiliki hubungan dengan $B E R$ dan probabilitas error dengan $\mathrm{Eb} / \mathrm{No}$ sebagai berikut :

$$
\begin{aligned}
& B E R=1 / 2-1 / 2 \text { erfc }\left\{0.354(\mathrm{~S} / \mathrm{N})^{1 / 2}\right\} \\
& \mathrm{Pb},{ }_{\text {BPSK }}=1 / 2 \text { erfc }\left\{(\mathrm{Eb} / \mathrm{No})^{1 / 2}\right\}
\end{aligned}
$$

Dalam penelitian yang dilakukan [9] diperoleh untuk harga $\mathrm{Eb} / \mathrm{No}=35 \mathrm{~dB}$ dicapai nilai BER sangat rendah $\left(10^{-7}\right)$ dengan harga CP sama dan atau lebih besar dari 4 simbol. Tapi dengan meningkatnya $\mathrm{CP}$ memiliki efek negatif pada efisiensi bandwidth. Oleh karena itu, ada CP optimal untuk meminimalkan tingkat kesalahan bit. Nilai ini sama dengan channel delay spread, yang dalam kasus kanal yang disimulasikan sebanyak redaman refleksi yang diambil. Untuk Eb/No kurang dari $20 \mathrm{~dB}$, CP tidak memiliki pengaruh karena efek noise dominan dibanding efek multipath.

\section{METODE}

Pada penelitian ini, penulis melakukan simulasi OFDM dengan tool Matlab, dengan membatasi lingkup dari blok mapper modulator di sisi transmitter sampai demapper di receiver berjenis BPSK untuk kanal additive white gaussian noise (AWGN).

\section{A. Parameter}

Parameter simulasi yang diambil meliputi :

\section{TABEL I. PARAMETER SIMULASI}

\begin{tabular}{|l|l|}
\hline Spasi kanal (sampling rate) & $20 \mathrm{MHz}$ \\
\hline Spasi frekuensi subcarrier & $0,3125 \mathrm{MHz}$ \\
\hline Jumlah simbol OFDM & 50.000 \\
\hline Durasi simbol untuk data & $3,2 \mu \mathrm{s}$ \\
\hline Periode total simbol OFDM & $4 \mu \mathrm{s}$ \\
\hline Bit per simbol OFDM & 52 \\
\hline Jumlah subcarrier & 52 \\
\hline Indeks subcarrier & $-26 \mathrm{s.d}-1 ;+1 \mathrm{s.d} \mathrm{26}$ \\
\hline FFT sampel poin & 64 \\
\hline Cyclic prefix (CP) & $8 ; 32$ \\
\hline Skema modulasi & BPSK \\
\hline Kanal radio & AWGN \\
\hline
\end{tabular}

\section{B. Hasil Simulasi}

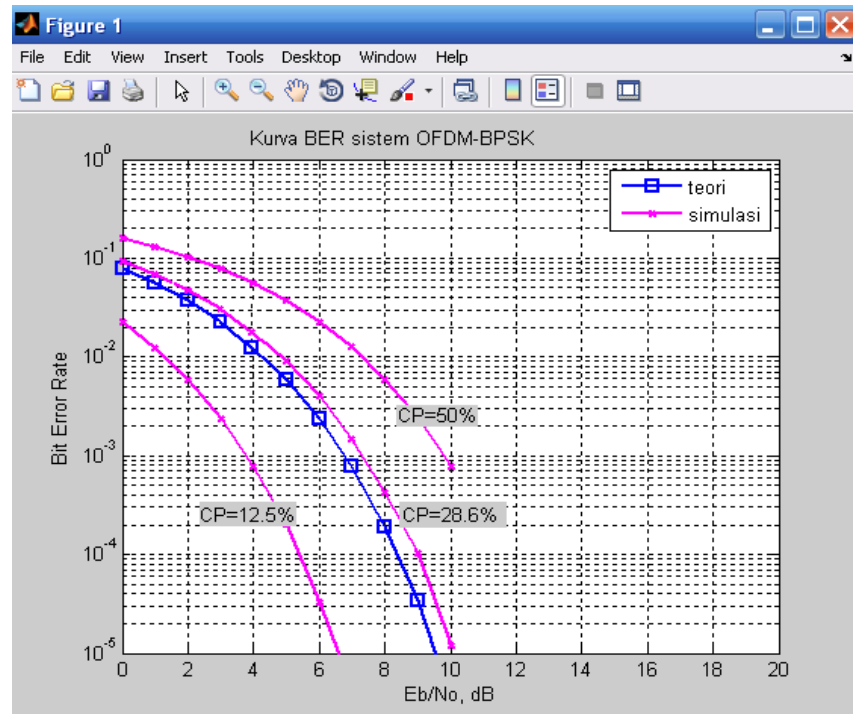

Gbr.7 Kurva BER simulasi

Berdasarkan simulasi yang dilakukan pada jumlah bit konstelasi sebesar jumlah subcarrier dengan hasil pada Gbr.7 di atas, terlihat bahwa pada CP sebanyak 12,5\% titik kurva berada di bawah harga teoritis , artinya nilai Eb/No lebih kecil dari yang diinginkan untuk harga BER yang sama. Sebaliknya 
semakin menaikkan persentase titik CP terhadap FFT/IFFT diperoleh nilai $\mathrm{Eb} /$ No yang semakin membesar pada nilai BER yang sama. Dengan demikian peningkatan cyclic prefix ini dapat menaikkan kinerja sistem sampai dengan sejumlah $\mathrm{CP}$ optimum tertentu yang diinginkan. Harga BER yang aman $0,9 \times 10^{-5}$ untuk Eb/No $10 \mathrm{~dB}$ pada simulasi ini diperoleh pada maksimum CP 28,6\%. Kisaran BER sebesar $10^{-4}$ adalah contoh harga BER threshold yang masih ditolerir untuk kebanyakan operasional perangkat komunikasi wireless digital.

\section{KESIMPULAN}

Dengan mempertimbangkan efisiensi energi spektrum, semakin menaikkan titik CP bahkan sampai $50 \%$ pada harga $\mathrm{Eb} / \mathrm{No}$ yang diinginkan akan berakibat menambah laju kesalahan bit mendekati $10^{-3}$ sehingga sangat menurunkan kinerja sistem OFDM-BPSK yang ada.

\section{REFERENSI}

[1] D.W.Astuti,"Analisa Simulasi Performansi Penggunaan Orthogonal Frequency Division Multiplexing pada Sistem Digital Video Boadcasting-Terrestrial," Jurnal IncomTech UMB Jakarta,vol.3,no.1, pp.65-84, 2012.

[2] R. Hidayat , "Ortogonalitas dan Simulasi Performa Sistem OFDM", Jurnal Tekno Efisiensi KOPERTIS Wilayah IV, vol.1, no.1,pp.30-37, Mei 2016.
[3] V.Tarokh, New Directions in Wireless Communications Research. Spinger, 2009.

[4] P.Wikanta, "Simulasi Pengaruh Penambahan CP pada Modulasi OFDM di Spesifikasi 802.11a/g yang Melewati Kanal Multipath Proakis ," Politeknik Negeri Batam, unpublished.

[5] Orthogonal Frequency Division Multiplexing (OFDM) Tutorial. www.complextoreal.com.

[6] R.Prasad, OFDM for Wireless Communication System, Boston : Artech House Inc., 2004.

[7] E.V. Mittal and S.R. Mittal, "A Cyclic Prefix OFDM System with BPSK Modulation ", Global Journal of Researches in Engineering Electrical and Electronics Engineering, Vol.12 Issue 7, Global Journals Inc. (USA), 2012

[8] Y.S. Cho, J. Kim, W.Y.Yang and C.G. Kang, MIMO - OFDM Wireless Communication with Matlab, Singapore : John Wiley \& Sons, 2010.

[9] I.F.C. Haubrich, "Theory and Simulation of a Wireless Communication System Based on Orthogonal Frequency Division Multiplexing. The limitations of OFDM in Comparison with a Singlecarrier System". Eindhoven University of Technology, p.38-46,2000. 